\title{
Characteristics of Students' Mental-Modeling Ability Based on Physics Problem Solving
}

\author{
Supriyadi \\ Dept. of Physics Education \\ UniversitasMusamus \\ Merauke, Indonesia \\ Jusman Mansyur \\ Dept. of Mathematic and Science Education \\ UniversitasTadulako \\ Palu, Indonesia \\ jusman_mansyur@untad.ac.id
}

\author{
Muh. Rizal \\ Dept. of Mathematic and Science Education \\ UniversitasTadulako \\ Palu, Indonesia
}

\begin{abstract}
This research aimed to explore and to describe characteristics of mental-modeling abilities (MMA) of prospective physics teachers based on physics problem-solving activity. Respondents of the research were two students from a selection test. The selected respondents were two categories (in their group) based on the test items, namely high and low category. The data of students' MMA were collected using specific physics problems where the students asked to represent and manipulate a certain representation. Results of the research showed that the students' MMA were influenced by four aspects, i.e.: knowledge, comprehension, the ability to make-connection of concepts, and experience in solving physics problems.
\end{abstract}

Keywords-Mental-modeling ability; physics problem-solving; knowledge; comprehension; experience

\section{INTRODUCTION}

Physics is a subject which has relevance to students' daily life. They can find a connection between the existing concept and phenomenon of the daily life. In that respect then, the role of mental models in learning becomes very important [1]. No exception in learning physics.

In order to understand what is learned (physics), students need the ability to build a mental model that includes basic theory and prediction of scientific work based on the model [2]. Thinking process requires building a good mental model [3]. Someone who is not able to build a mental model of the person will cause difficulties in developing thinking skills, including problem-solving.

The ability of students to solve a problem is not only derived from the results of scientific work but can also be obtained from the experience of students in the interpretation of an event. It was concluded that when the student can solve a problem, not necessarily students have the right mental model.

A mental model is a representation of a person's internal formed from interaction with the environment [4]. In another study states that the mental model is an internal representation structure that acts as an analog of a situation or process [5]. can say that mental model is a representation of a person's internal model of the environment.

The result of the interaction between the internal representation and the environment cannot be measured as long as the internal representation form. This is supported by research [3]. He stated that it was not an easy task to be able to know what is thought by learners in solving problems, especially if it cannot be seen by the eye. To be able to measure the shape of the internal representation of learners, we can see it through its external representation. Ref. [6] states that the internal representation can be deduced or inferred based on external representation in a variety of conditions; for example from disclosure through words (verbal), through writing in the form of symbols, images, graphics, tables or through props (hands-on).

Cognitive psychologists often use academic studies on mental models to obtain information about the processes of thinking, especially in problem-solving [1]. The research reinforced the previous research by [7]. Ref. [7] believes that the concept of students 'knowledge, MMA, and the benefits of mental models affect the reconstruction of students' understanding of the molecular polarity.

Ref. [7] proposed the new questions about how the role of MMA itself in physics problem-solving (PPS). Trying to answer that problem, [8] conducted a research which focused on the problem of representation. The research is devoted to the relationship between the order of translation and integration issues at the completion of physics problem-solving. From the research found the students and teachers most do not integrate into the use of a diagrammatic representation completion of PPS. Ref. [2] tried to describe any aspect that affects MMA someone on the basic concept of static electricity. He expressed modeling as one of the main processes in the development of science and therefore has the potential to induce changes in learning approaches. 
Based on the translation of the above it can be stated that it is necessary to do a study on the mental characteristicsmodeling ability of students in solving physics problemsolving. Through such studies can be seen characters and the factors that affect the mental-modeling ability of students.

\section{METHODS}

This research used a qualitative descriptive approach. The research subject is physics student teachers who have attended the second year of the course Physics I. The respondents in this research were two students were selected based on a selection test respondent. Selected respondent is divided into two categories (in the group) based on mastery of concepts, namely high and low categories. Furthermore, selected respondents, engage in activities thinking aloud, followed by semistructured interviews to obtain data on the characteristics of MMA.

The research instrument in this study consists of the main instruments that the researchers themselves while supporting instruments composed of respondent selection tests, test exploration MMA with the characteristics of problem-solving and interview guides.

Data obtained from thinking aloud and interviews made in the form of a transcript of thinking aloud and interview results are then read repeatedly and analyzed under the rubric of MMA (Table I) which adapts Ref. [7].

\section{SECTION I. TABLE CATEGORIZATIONMODELMENTAL ABILITY} (MMA)

\begin{tabular}{|c|c|c|}
\hline No. & MMA Characteristics & Score \\
\hline \multirow{3}{*}{1} & $\begin{array}{l}\text { Producing a mental model in the form of representation } \\
\text { diagram/graph }\end{array}$ & 2 \\
\hline & $\begin{array}{l}\text { Producing a mental model based on the representation } \\
\text { of diagram/graph or another relevant form of } \\
\text { representation }\end{array}$ & 1 \\
\hline & Unable to generate any form of representation & 0 \\
\hline \multirow{3}{*}{2} & $\begin{array}{l}\text { Being able to manipulate mental models based } \\
\text { propositions }\end{array}$ & 4 \\
\hline & $\begin{array}{l}\text { Having a mental model of rigid and concluded that this } \\
\text { form of mental models cannot be changed when a new } \\
\text { proposition is added to the model, often need to be } \\
\text { based on the model of the concrete }\end{array}$ & 2 \\
\hline & $\begin{array}{l}\text { unable to use this form of representation whatsoever } \\
\text { based propositions exist }\end{array}$ & 0 \\
\hline \multirow{3}{*}{3} & $\begin{array}{l}\text { monitoring the metacognitive process of drafting a } \\
\text { mental model }\end{array}$ & 4 \\
\hline & $\begin{array}{l}\text { perform self-check using other approaches to test or } \\
\text { check the mental models to identify the error of the } \\
\text { mental model }\end{array}$ & 2 \\
\hline & $\begin{array}{l}\text { process metacognitive monitor the preparation of the } \\
\text { mental model }\end{array}$ & 0 \\
\hline & $\begin{array}{c}\text { Total Maximum } \\
\end{array}$ & 10 \\
\hline
\end{tabular}

\section{RESULTS AND DISCUSSION}

\section{A. HMMA Characteristic}

Respondents first getting a score of 8 when solving physics problem solving, as well as in the category HMMA. When working on the problems of PPS, RKT often paused and then try to resolve the matter of PPS. Researchers speculate that habit as part of an internal representation of respondents in solving problems. When stopped, the respondents seemed to try to collect information on the matter and tried to organize his mental models. It looks after the pause, which researchers consider to be a certain physical activity, respondents directly wrote the information he gets questioned.

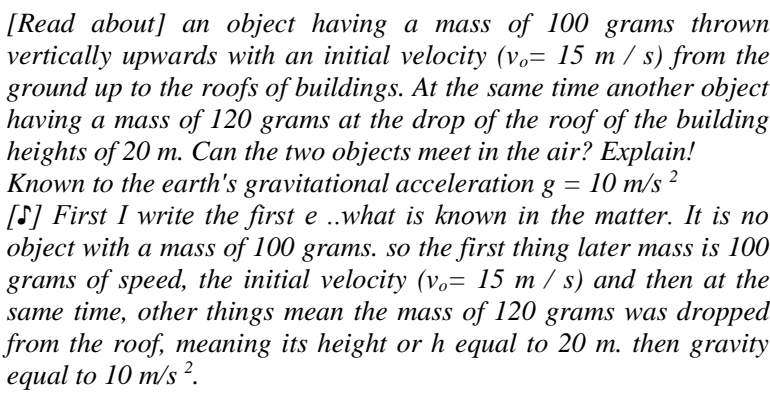

As for the form of external representation, the respondent produces a form of external representation in the form of a free diagram. It can be seen in the written answer respondents and respondent's conversation on TA "...It could also be drawn, likened by a ball...". From researchers believe that the respondent has been able to produce a mental model in the form of graphs/diagrams in accordance with the characteristics of one category of MMA. From what respondents generate respondents are entitled to receive a maximum score of 2 .

[Drawing ball] thrown vertically upwards with initial velocity $15 \mathrm{~m}$ I $s$ with the other [drawing separately] was ... was dropped from the roof with a height of $20 \mathrm{~m}$.

Means here the first thing that e motion vertically upwards, then the second body moves in free fall [ $\delta]$

The question whether the two objects meet in the air?

Interesting findings obtained from the respondents is where respondents separately draw drawing two objects. As well as to resolve the PPS. Respondents using two equations separately. As a result, the final answer of respondents did not correspond to the desired matter. From the data obtained from interviews, may be the intention of respondents in solving separately is.

$\begin{array}{ll}\text { Interviewer: } & \text { Based on the free diagram that you created, the } \\ \text { object } 1 \text { and object } 2 \text { separate drawing. That is for } \\ \text { what? } \\ \text { RKT: } \\ \text { Interviewer: } \\ \text { What revealed to movement } \\ \text { The image it is necessary or not? } \\ \text { the } \\ \text { As for me, Ineed a picture. Because usually there, } \\ \text { there, let revealed to the logic of how it fell. } \\ \text { Which is only } 20 \text { meters to } 11.75 \text { meters only } \\ \text { means only nearly half the height of the second } \\ \text { object so. Let revealed to. Usually, no Figs were } \\ \text { not obtained results can be estimated from the } \\ \text { image. }\end{array}$

From the transcript of the interview, the researcher can see that the respondent tried to manipulate mental models and try to construct back in the form of mathematical representation. Respondents analyze the information he could in a diagrammatic representation made in the form of a mathematical representation to include that information in the equation. This indicates that respondents meet three characteristics of MMA and got a maximum score of 4 . 
As for the characteristics of the third, researchers believe the respondent has been unable to perform a self-check in metacognition process of formulating mental models. Where the ability to monitor the construction process in metacognition

can form mental models through modeling[9]• Respondents were not able to do it right. This is apparent from the written answers respondents and transcript excerpts TA where the final answer of respondents did not correspond to the answers to the PPS. This is shown in the following transcript.

From the state of matter is in fact the question is whether the two bodies may meet in the air already [paused] can certainly meet but not collide meant to meet because that is the only dropped from the top of the other from below, to find the time dibola first it was the same also wear tequal with roots $2 \mathrm{~h} / \mathrm{g}$.

Because the heights he achieved $11.75 \mathrm{~m}$ e direction different but the other one down the other up.

[Pause] [Recalculate] [gained 1.4 second, 2 seconds of the second body means the first thing faster motion than the second object so (analyze) met but at the height ... not met.

From the transcript shows that the respondent changed the final answer. Here we can see that respondents perform a selfcheck, but the self-check performed produces incorrect answers. Answer resulting from the self-check does not correspond to that desired by the matter of PPS. Researchers suspect this is also related to how respondents describe or simulate falling objects separately so that the respondents did not get the final answer accordingly. Factors that lead to this error because of a lack of the ability of respondents in linking concepts and little or no familiarity of respondents in practice do the problems PPS. By looking at the written answer, TA transcript, and interviews, the researchers gave a score of 2 for the characteristic 3 .

Here is presented a written answer respondents' result sheet that became the basis of scoring the MMA category of respondents. As shown in Fig 1.

In the category HMMA, Respondents were able to build a mental model in the form of a diagrammatic representation, has the ability to manipulate mental models, and can perform a self-check to test the mental model [1]. At HMMA respondents could generate 3D models and manipulate mental models [7]. Not all of the characteristics of MAA fulfilled in RKT. Although RKT in the category HMMA but several factors can affect a person MMA. Key to the success of the first step problem solving it's not the separation of the preparation of diagrams with other stages such as the compilation of information and the identification of variables [8].Viewable RKT is unfamiliar in processing physics of problem-solving capability though MMA has begun to form.

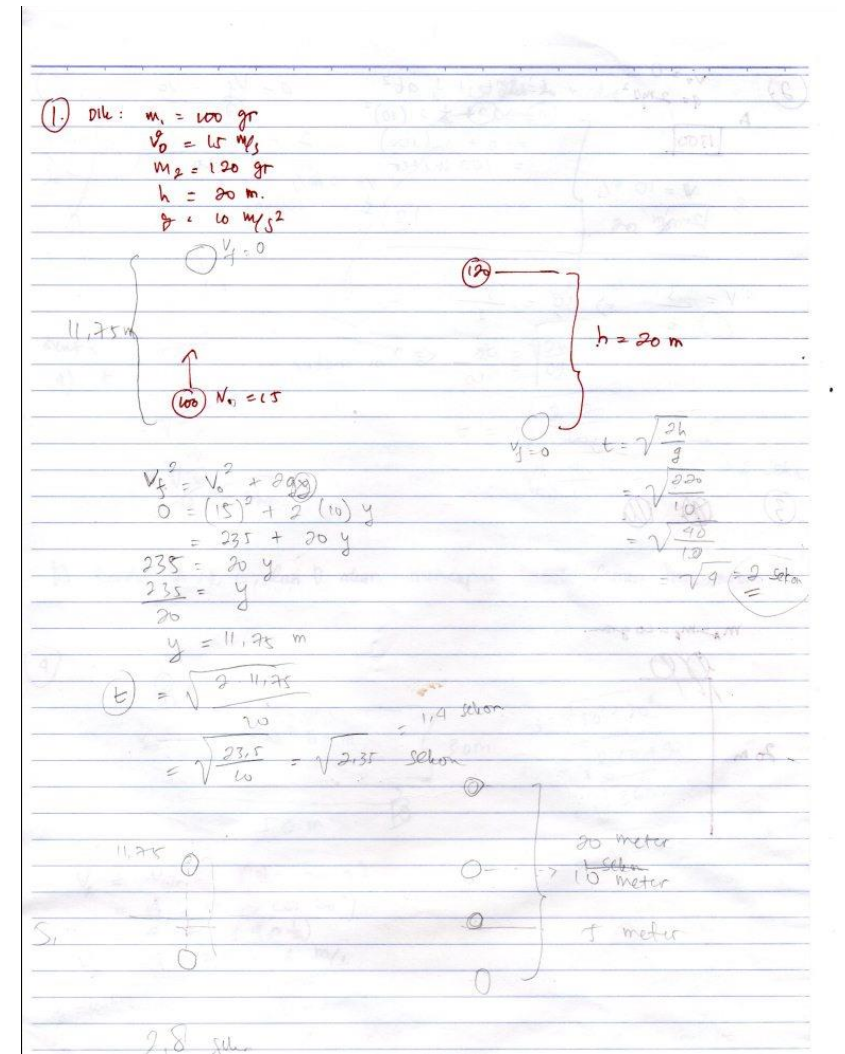

Fig. 1. Written answer RKT

\section{B. LMMA Characteristic}

TA transcript of respondents RKR showed that in solving PPS, respondents first read about it thoroughly and even repetitive. Alleged researchers, this is a form of internal representation. Where the respondent tried to collect the information contained in the matter.

Although the shape of the external representation produced by the respondent is a form of mathematical representation, it appears that the respondents do it quite structured and trace. After reading the questions and repeating, respondents listing the information by writing what is known and asked in the matter and put a number in the equation is considered correct.

[...] Given: The first object of mass 100 grams thrown vertically with a speed $v_{o}$ speed initially $15 \mathrm{~m} / \mathrm{s}$ continues to object that the mass is 120 grams was dropped on the building at the height $h=20$ meters

Is being asked: When two objects meet in the air (at what height $h=$ .....?)

Completion: For example, the equation $s=v_{o} t+1 / 2 g t^{2}$.

Based on the written answer and transcript TA the researchers gave a score of 1 for characteristic 1 MMA. From the transcript of TA follows "... Because of the known $h$ total $=$ 20 meters then $h 1+h_{2}$ should be $20 \mathrm{~m} \ldots$... or from the statement of respondents stated that "... because the object is thrown vertically has an initial velocity then ..." and "... Because of the object, this is the free fall motion $v_{0}$ does not exist ... "show that although generate a mathematical 
representation forms, the respondents showed a good understanding of the concept.

Form external representation produced by the respondent is a form of mathematical representation so that researchers thought that the respondents had difficulty in visualizing the internal representation into a form of external representation in the form of graphs/diagrams. It is reinforced by the statement in the respondent seen in the transcript of the interview.

Natural finish is a matter separately.

$\begin{array}{ll}\text { Interviewer: } & \text { Did you ever encounter a problem like this? } \\ \text { RKR: } & \text { Never think, ever. } \\ \text { Interviewer: } & \text { What effect did not previously learned when } \\ & \text { solving this problem? } \\ \text { RKR: } & \text { Influential once, because it has been learned so } \\ & \text { ehmm, how ya, than I look matter that I never } \\ & \text { learned at all, right easier I see the questions that } \\ & \text { I've learned so staying recall } \\ \text { Interviewer: } & \text { You see exactly, or what? } \\ \text { RKR: } & \text { No, just the same concept } \\ \text { Interviewer: } & \text { Difficulty in doing all a matter of what? } \\ \text { RKR: } & \text { Lack of practicing. Because of lack of practicing } \\ & \text { so forget }\end{array}$

Here it can be seen that the respondents rely on the memory of the matter PPS similar so just enter the numbers into the equation. As a result, the respondent has a mental model of rigid and difficulty in solving the abstract form. Researchers gave a score of 2 for the characteristics of the second MMA. From the transcript of the interview follows also seen that knowledge and understanding are also greatly affected a person MMA.

$\begin{array}{ll}\text { Interviewer: } & \text { questioned number one, right there determine } \\ & \text { the positive and negative signs, so how do you } \\ & \text { define it? } \\ \text { RKR: } & \text { delusional. It should be stated in the picture, it's } \\ & \text { just him, do not understand so only through the } \\ & \text { imagination alone. }\end{array}$

Knowledge and understanding less of respondents coupled with the lack of experience solving PPS respondents made respondents were unable to perform process self-check metacognitively or test other to approach to their work. Researchers gave a score of 0 to a characteristic third of MMA. Although the concept of the answers of the respondents correctly but does not indicate that respondents understand and know about the existing concept in question. PPS. It can be seen from the statement of the respondent contained in the following interview transcript.

$\begin{array}{ll}\text { Interviewer: } & \text { For about number one, if we can draw } \\ & \text { diagrams/graphs? } \\ \text { RKR: } & \text { Hmm yes, it could. } \\ \text { Interviewer: } & \text { Why not drawn? } \\ \text { RKR: } & \text { Because my understanding has not been up } \\ & \text { there. That is if for, like everything to make } \\ & \text { diagrams that do not yet understand. } \\ \text { Interviewer: } & \text { Is not that diagram will help us resolve } \\ & \text { the problem? } \\ \text { RKR: } & \text { Yes, this also but I do not understand }\end{array}$

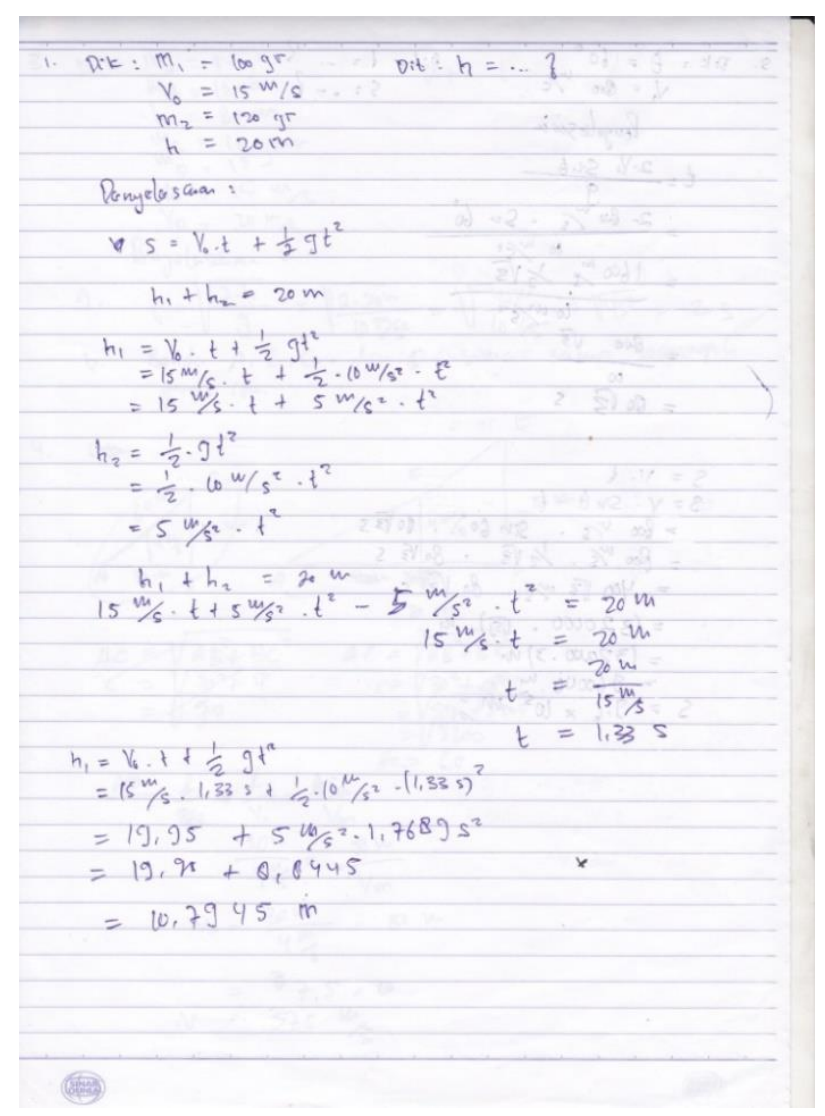

Fig. 2. Written answer RKR

From the above explanation illustrates that respondents in the category LMMA have a limited understanding to produce mental models. Backed by the research results Rahmiliaet al where the category LMMA, mental models generated with the instructions given by [2]. Written answer LMMA categories of respondents indicating the absence of a diagrammatic representation made form and interpretation of the researcher to answer according to the results of the study of money. Students in the category LMMA just trying to recall based on long-term memory and rarely represented in the mental representation [7]. Hutagaol stated that the use of numbers in the generalized symbol is something that is difficult for students [6]. It is also found in this study in which the PPS completion of the respondents was unable to make representations in the form of diagrams

\section{Level's MMA Respondent}

Has been carried out a review of written answers, transcripts thinking-aloud, and the transcript of the interview to the respondent. Assessing the do against MMA student characteristics based on the interpretation of the researchers on the external representation of the respondents[10]. Results of the study showed that the MMA category respondents divided on mental high-modeling ability(HMMA), and low mentalmodeling ability(LMMA). The category is obtained based on the average score of respondents MMA. The scoring refers to the characteristics of MMA student section is modified based on the characteristics that made by Wang [7]. In addition to the 
score sheet MMA exploration work, to strengthen the existing data conducted interviews TA and then made a transcript. To facilitate the categorization, do stretching MMA score adapted from [2] Categories done by reviewing the MMA scores mean $(\bar{x})$, namely:

$\begin{array}{lll}\text { HMMA } & : & 7<\bar{x} \leq 10 \\ \text { MMMA } & : & 3<\bar{x} \leq 7 \\ \text { LMMA } & : & 0 \leq \bar{x} \leq 3\end{array}$

From the stretching score refers to a section, obtained a score as shown in Table II.

TABLE II. SCORES OF ACQUISITIONS MMA

\begin{tabular}{|c|c|c|c|c|c|}
\hline \multirow{2}{*}{ Respondent } & \multicolumn{3}{|c|}{$\begin{array}{c}\text { MMA } \\
\text { Characteristics }\end{array}$} & \multirow{2}{*}{ Average } & \multirow{2}{*}{ Category } \\
\hline & 1 & 2 & 3 & & \\
\hline RKT & 2 & 4 & 2 & 8 & HMMA \\
\hline RKR & 1 & 2 & 0 & 2 & LMMA \\
\hline
\end{tabular}

The table above shows that respondents in the category HMMA first and second respondents in the category LMMA. Based on research conducted by [5], mental models cannot be generalized and depends on the context. Thus, the above results represent only MMA kinematics of respondents in concept only. Category performed based on the description of MMA characteristics of each respondent.

\section{CONCLUSIONS}

Based on data analysis can be concluded that the level of MMA student greatly influenced by the ability of students raises each characteristic MMA. There is a close connection between the characteristics with other characteristics. Students' ability to manipulate mental models rely heavily on the form of the earliest representations generated. Students HMMA category can produce a representation in the form of a diagram that can easily manipulate mental models. Student category LMMA produces its initial representation mathematics representation depicting their mental models are rigid.

Self-check is used to monitor the mental models. Students category HMMA able to do a self-check of the mental models produced from the manipulation of the model. Unlike the RKR who cannot manipulate mental models due to mental models held rigid and limited.

There are factors that affect the mental models of students, especially in the matter of kinematics. Factors obtained in this study correspond to those obtained by [2]. These factors are knowledge, understanding and the ability to connect the concepts in kinematics as well as written material that the experience factor can be trained by working about PPS (learning experience). These factors are interrelated and able to influence each other.

\section{ACKNOWLEDGMENTS}

We would like to thank Directorate of Higher, Ministry of National Education and Culture of Indonesia for funding this research in Hibah Tim Pascasarjana 2017 contract number: 696c/UN28.2/PL/2017. Secondly, we wish to thank I Komang Werdhiana for this validation and valuable discussion.

\section{REFERENCES}

[1] Sunyono, L. Yuanita, and M. Ibrahim, "Mental Models of Students on Stoichiometry Concept in Learning By Method Based on Multiple," Online J. New Horizons Educ., vol. 5, no. 2, pp. 30-45, 2015.

[2] S. Rahmilia, J. Mansyur, and S. Saehana, "MENTAL-MODELING ABILITY MAHASISWA," in Seminar Nasional Fisika dan Pendidikan Fisika, 2014, vol. 5, no. 2, pp. 71-76.

[3] N. Didiş, A. Eryllmaz, and Ş. Erkoç, "Investigating students' mental models about the quantization of light, energy, and angular momentum," Phys. Rev. Spec. Top. - Phys. Educ. Res., vol. 10, no. 2, pp. 1-28, 2014.

[4] V. der V. G, "Mental Model of Incidental Human-Machine Interaction.," 2015. [Online]. Available: http://cs.vu.nl/ gerrit/mmi9910report1.doc.

[5] Ö. Özcan, "Investigating students ' mental models about the nature of light in different contexts," Eur. J. Phys., vol. 36, no. 6, pp. 1-16, 2015.

[6] K. Hutagaol, "Multi representasi dalam pembelajaran matematika," in KNPM V Himpunan Matematika Indonesia., 2013, pp. 132-138.

[7] C. Y. Wang and L. H. Barrow, "Characteristics and Levels of Sophistication: An Analysis of Chemistry Students' Ability to Think with Mental Models,” Res. Sci. Educ., vol. 41, no. 4, pp. 561-586, 2011.

[8] J. Mansyur, "Teachers' and Students' Preliminary Stages in Physics Problem Solving," Int. Educ. Stud., vol. 8, no. 9, pp. 1-14, 2015.

[9] J. Mansyur and Darsikin, "Enhancing Direct Instruction on Introductory Physics for Supporting Students' Mental-Modeling Ability," Int. Educ. Stud., vol. 9, no. 6, p. 32, 2016.

[10] G. Chittleborough and D. Treagust, "Correct interpretation of chemical diagrams requires transforming from one level of representation to another," Res. Sci. Educ., vol. 38, no. 4, pp. 463-482, 2008. 